\title{
A clinical study investigation the three months prognosis of patients with ischemic stroke treated with recombinant tissue plasminogen activator (rt- PA) and its effective factors
}

\author{
Vahid Abbasi ${ }^{1}$, Abolfazl Atalu ${ }^{1 *}$, Afshan Sharghi ${ }^{2}$, Fatemeh Taghvatalab ${ }^{3}$ \\ 'Department of Neurology, Ardabil University of Medical Sciences, Ardabil, Iran \\ 2Department of Community Medicine, Ardabil University of Medical Sciences, Ardabil, Iran \\ ${ }^{3}$ Faculty of Medicine, Ardabil University of Medical Sciences, Ardabil, Iran
}

\author{
Received: 19 January 2019 \\ Accepted: 13 April 2019 \\ Published online: 27 April 2019 \\ *Corresponding author: Abolfazl \\ Atalu, Tel: 045-33249973 \\ Address: Moallem street, Alavi \\ Hospital, Ardabil, Iran. \\ Email: a.atalu2018@gmail.com \\ Competing interests: None. \\ Funding information: This study \\ was financially supported by Ardabi \\ University of Medical Sciences. \\ Citation: Abbasi V, Atalu A, Sharghi \\ A, Taghvatalab F. A clinical study \\ investigation the three months \\ prognosis of patients with \\ ischemic stroke treated with \\ recombinant tissue plasminogen \\ activator (rt-PA) and its effective \\ factors. Journal of Emergency \\ Practice and Trauma 2019; 5(2): 47- \\ 50. doi: 10.15171/jept.2019.05.
}

\begin{abstract}
Objective: Currently, treating ischemic stroke by intravenous thrombolytic therapy has acceptable results in patients with stroke. This study aimed to evaluate the three months prognosis of patients treated with recombinant tissue plasminogen activator (rt-PA).

Methods: This cross-sectional prospective study was conducted on 30 patients with cerebral ischemic stroke with the National Institutes of Health Stroke Scale (NIHSS) $>5$. Data such as demographic information, signs and symptoms, medical history, risk factors, focused neurological examination, and the NIHSS were collected for all patients. Then, all patients received $0.9 \mathrm{mg} / \mathrm{kg}$ of rt-PA as intravenous bolus doses and intravenous infusion under close monitoring in the emergency department. All patients were checked for necessary outcomes and also disability at the admission time, 7 days later and after three months all patients were checked again. All collected data were analyzed by appropriate tests using SPSS version 22 . Results: Of all patients, $63.3 \%$ were males and $36.7 \%$ were females. The mean age of the patients was $62.37 \pm 12.62$ years with a range of $40-91$ years. The mean of NIHSS was 12.46 \pm 4.28 at admission time, in day seven it was $8.06 \pm 3.72$ and in month three after treatment it was $3.62 \pm 2.31$. There was a significant relationship between age, place of residence and NIHSS. Thirty percent of patients had NIHSS more than 15 at admission time and after 7 days this rate reached to $10 \%$ and three months later it declined to $6.7 \%$. These differences were statistically significant.

Conclusion: Intravenous thrombolytic therapy is associated with proper short term results in most patients with ischemic stroke.

Keywords: Prognosis, Ischemic stroke, Recombinant tissue plasminogen activator, Ardabil
\end{abstract}

\section{Introduction}

Stroke refers to any vascular injury that reduces brain blood flow in the brain area and leads to brain neurological impairment. About $80 \%$ of brain strokes have an ischemic origin due to the obstruction of the cerebrospinal fluid and the rest is hemorrhagic which occurs due to intracerebral hemorrhage $(\mathrm{ICH})$ or subarachnoid hemorrhage $(1,2)$. Stroke is the most common neurological disorder in the world and the most important cause of disability in different countries. The mortality rate of acute stroke in the first month of incidence is about $10 \%$, and the rest is accompanied by a neurological defect (3-5). Usually, $50 \%-70 \%$ of patients return to their initial function, $15 \%-30 \%$ are permanently incapacitated and $20 \%$ need hospital care for three months. Although stroke is a disease which affects the elderly more, but one third of the patients are under the age of 65 (6). Strokes impose a very high cost to the health system of countries. Studies on the prevalence of acute stroke in Iran show that it is similar to that of Arab neighborhoods, and it is less than that of advanced countries. In the past, stroke treatment included stabilization, care and restoration of patients, but today with a better understanding of the pathophysiology of nerve damage and the new drugs, the treatment of the disease includes controlling the blood pressure using anticoagulants and thrombolytic drugs as well as invasive interventions with catheters and surgery $(7,8)$.

Many studies have been conducted on the efficiency of recombinant tissue plasminogen activator (rt-PA) and findings have revealed acceptable outcomes concerning the prescription of this drug between 3 and 4.5 hours after the onset of the symptoms (9). 
However, the use of this drug requires the proper awareness of the society in identifying stroke symptoms, early referral of patients, the quality of life, speed of laboratory and imaging services, timely visits by neurologist, early treatment and observing certain clinical principles $(10,11)$. Due to several preventive factors in the prescription of the drug, only a small percentage of patients could receive the rt-PA (12). In 1996, the US Food and Drug Administration (FDA) approved the use of rt-PA in the treatment of ischemic stroke (13). According to the last guideline of the United States Cardiovascular and Stroke in 2010, intravenous rt-PA administration is considered to be the most effective treatment intervention in stroke. The use of rt-PA due to reduced patients' inability, reduced hospitalization time and long- term treatment have saved millions of dollars and consequently the use of rt-PA for the treatment of stroke has increased. Due to the lack of infrastructure, expensive drugs, complications from administration of rt-PA and its low golden time from the onset of symptoms to prescription, its use has been limited. So, Thrombolytic therapy, despite the increased risk of bleeding (4.6\%), reduces morbidity and mortality in patients with acute ischemic stroke $(14,15)$. The aim of this study was to evaluate the clinical course and the prognosis of patients with cerebral ischemic stroke treated with rt-PA and its effective factors during three months.

\section{Methods}

This cross-sectional prospective study was undertaken on 30 patients with ischemic stroke and the National Institutes of Health Stroke Scale (NIHSS) > 5 who were hospitalized in the neurology department of Alawi hospital in Ardabil during 2016-2018. Stroke confirmation was performed by a neurologist based on clinical symptoms and imaging. The inclusion criteria encompassed the age more than 18 , patients referred to the hospital less than 4.5 hours after the onset of symptoms and the indication of rt-PA injection. The exclusion criteria included ICH, subarachnoid and subdural hemorrhage, contra indication of rt-PA use and having cerebral venous sinus thrombosis. The single dose of $0.9 \mathrm{mg} / \mathrm{kg}$ of rTPA within 3 to 4.5 hours after the start of stroke was injected intravenously for all patients and they were asked to return three months later for a final check.
We collected data by a checklist in two steps. First, at baseline data concerning the guidelines for indication and contraindication of rt-PA prescription were collected using form 1. Based on form 2, Modified Rankin Scale and NIHSS were completed for all patients. Data were also gathered 7 days later. By the same token, all clinical and imaging findings as well as other clinical examination findings were checked for all referred patients and entered in a checklist. Three months later, NIHSS was evaluated for all patients who referred to the hospital. In order to evaluate patients' disability, doctors checked the movement of eyes, legs, visibility, arm movement, facial paresis, limb ataxia, ability to speak and sensory impairment, dysarthria, extinction and neglect.

The NIHSS has 11 questions with scores from 0 (the lowest) to 4 (the highest). The minimum obtained score for the questionnaire is 0 and the maximum is 44 .

Collected data were analyzed using descriptive statistics such as table and graph and also analytical statistics such as t-test to compare the mean of score between the two groups. Also, ANOVA test was used to compare the mean of score between three groups. All tests were conducted using SPSS version 22. $P$ value less than $5 \%$ was considered significant.

\section{Results}

Of all patients, $63.3 \%$ were males and the rest were females. There was no significant relationship between gender and NIHSS at the time of admission, on the seventh day and the third month. The average age of the patients was $62.37 \pm 12.62$ years with a range of 40-91. Concerning the place of residence, $76.6 \%$ of the patients lived in urban (n $=23$ ) and the rest of them lived in rural areas $(n=7)$. There was a significant relationship between age, place of residence and NIHSS (Table 1). The average NIHSS in the first day was $12.46 \pm 4.28$, at the seventh day it was $8.06 \pm$ 3.72 and three months after treatment it was $3.62 \pm 2.31$. This difference was statistically significant (Figure 1). Regarding the NIHSS score, $30 \%$ of patients had a score above 15 at the time of admission. This score decreased to $10 \%$ on the seventh day and it declined to $6.7 \%$ in the third month. The difference was statistically significant (Figure 2). The mean time of patients' arrival until receiving rtPA

Table 1. Relationship between NIHSS, age and place of residence

\begin{tabular}{|c|c|c|c|c|}
\hline \multirow{2}{*}{ Characteristics } & & \multicolumn{3}{|c|}{ NIHSS } \\
\hline & & First day & 7 days later & 3 months later \\
\hline \multirow[t]{3}{*}{ Age } & $69-40(n=21)$ & $12.31 \pm 4.13$ & $7.82 \pm 3.44$ & $3.12 \pm 2.09$ \\
\hline & $\geq 70(n=9)$ & $13.26 \pm 4.71$ & $9.69 \pm 4.37$ & $54.2 \pm 1.4$ \\
\hline & $P$ value & 0.019 & 0.006 & 0.012 \\
\hline \multirow[t]{3}{*}{ Place of residence } & Urban $(n=23)$ & $12.28 \pm 4.36$ & $7.87 \pm 3.41$ & $3.35 \pm 2.12$ \\
\hline & Rural $(n=7)$ & $12.96 \pm 4.22$ & $8.34 \pm 3.86$ & $3.86 \pm 2.66$ \\
\hline & $P$ value & 0.017 & 0.033 & 0.038 \\
\hline
\end{tabular}




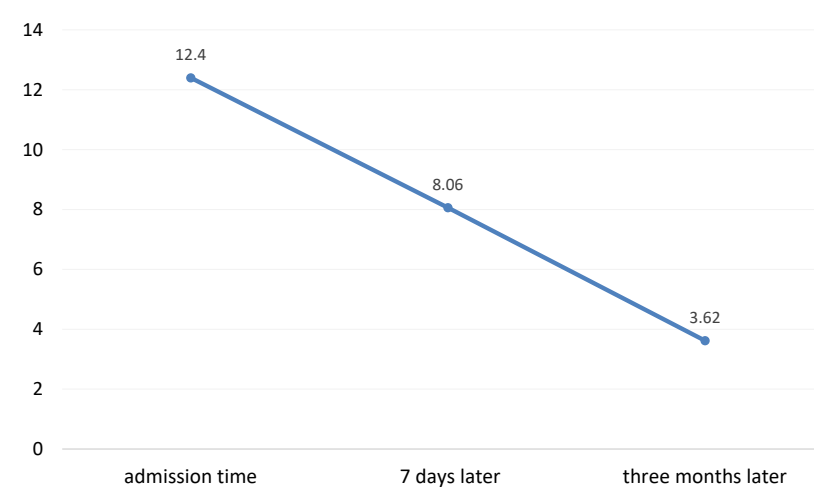

Figure 1. The changes of NIHSS rate during the study times.

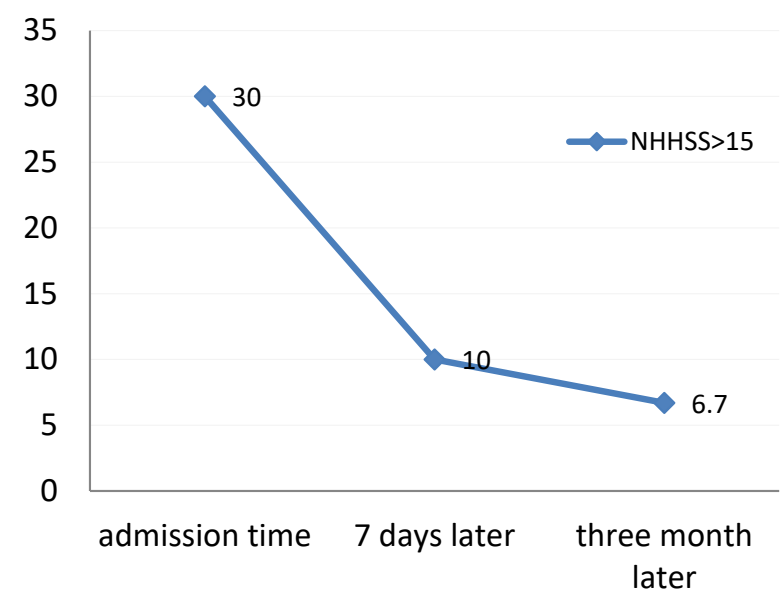

Figure 2. The trend of NIHSS $>15$ during the study times.

was $56.82 \pm 34.21$ minutes and the average duration of hospitalization in the stroke unit was $4.16 \pm 2.65$ days and the average number of hospitalization was $8.56 \pm 3.24$ days. These findings were statistically significant (Table 2). Ten percent of patients had ICH and 2 patients died.

\section{Discussion}

In this study, $63.3 \%$ of patients were males and $36.7 \%$ were females, but there was no significant relationship between sex and NIHSS. Emberson et al in a study in 2014 showed that having high age and stroke severity can increase the likelihood of ICH in the first few days after Activase (alteplase) therapy (16). In the present study, there was a significant relationship between age and NIHSS at all three times. Also, this study showed that Activase (alteplase) in the first 4.5 hours after stroke can improve the disease and lead to good outcomes in patients. In the present study, NIHSS score above 15 was also found in $30 \%$ of patients at admission time and it reached to $6.7 \%$ in the third month. Pashapour et al in a study in 2011 showed that thrombolytic therapy in ischemic stroke patients had short and intermediate results and in patients with small bowel obstruction the severity of the disease was less and recovery was in a high level (17). In 2013, Hatamabadi et al. in a study found that $30 \%$ of patients who received rt-PA had significant improvement during three months in comparison to patients who received placebo. In the present study the average NIHSS of patients at the time of arrival was 12.46 and it reached to 3.62 during three months. Also, in the above study, $\mathrm{ICH}$ in the placebo group was $0.6 \%$ and in the rTPA group it was $6.4 \%$. In addition, the motility rate was $21 \%$ in placebo group and $17 \%$ in rTPA group (18). Besides, we observed a significant relationship between the average score of NIHSS on the first day, seventh day and the third month after follow up with the severity of neurological defect. Campbell et al in a study in 2015 showed that rt-PA recipients had good clinical symptoms and CT scan within the first 4.5 hours (19). In this study the average time of arrival of the patient and receive rt-PA was $56.82 \pm 34.21$ minutes and the average duration of hospitalization in the stroke unit was $4.24 \pm 2.65$ days and the average number of admission days was $8.56 \pm 3.48$. These findings were statistically significant. According to the results of this study, 30\% of patients had a NIHSS score higher than 15 at the time of admission which after the treatment on the seventh day it reached to $10 \%$ and after three months it reached to $6.7 \%$. The results of the study conducted by Adams et al in 2007 showed that $6.4 \%$ of patients who received rTPA and $0.6 \%$ of patients receiving placebo had $\mathrm{ICH}$. Also, acceptable outcomes were correlated with the severity of deficiency and age so that patients with NIHSS $<20$ and age $<75$ had the best response to treatment (1). In the present study, there was a significant relationship between patients over 70 years and NIHSS levels at all three times.

\section{Conclusion}

This study showed that receiving the drug as soon as possible reduces the severity of post-stroke inability and if it is administered three hours after stroke, its outcome could be very beneficial to the patient during the treatment process. In order to minimize the time of referral by the

Table 2. Relationship between time of hospitalization by NIHSS

\begin{tabular}{|c|c|c|c|c|}
\hline \multirow[b]{2}{*}{ Variables } & & \multicolumn{3}{|c|}{ NIHSS } \\
\hline & & $\begin{array}{c}\text { First day } \\
P \text { value }\end{array}$ & $\begin{array}{c}7 \text { days later } \\
P \text { value }\end{array}$ & $\begin{array}{c}3 \text { months later } \\
P \text { value }\end{array}$ \\
\hline Mean of time from admission to receive rt-PA (min) & $56.82 \pm 34.21$ & $<0.001$ & $<0.001$ & 0.002 \\
\hline Mean of time hospitalized in ward of neurology (day) & $4.16 \pm 2.65$ & 0.007 & 0.003 & 0.005 \\
\hline Mean of total hospitalized days & $8.56 \pm 3.24$ & 0.014 & 0.011 & 0.017 \\
\hline
\end{tabular}


patient to the hospital and diagnose the disease, adequate facilities such as early diagnose, transferred and treated must be provided for all patients. It is suggested that extensive studies be conducted with a larger sample size in the future.

\section{Limitation}

A great deal of studies have been done concerning the limitation and barriers of the delivery or prescription of rTPA for patients with acute ischemic stroke and related factors. So, programing for raising the knowledge of people about the symptoms of stroke and providing more facilities in all hospitals could be essential in future.

\section{Authors' contributions}

VA participated in study design, data collection and clinical interview. AA helped in study design, examination of patients, and filling out checklist. ASH helped in analysis data and writhing the paper. FT helped in data collection and follow-up patients and writing thesis format.

\section{Ethical Issues}

The ethics committee of Ardabil University of Medical Sciences approved the study with code number IR.ARUMS.2017.88. In addition, this study was registered in Iranian Registry of clinical trials (IRCT) (identifier: IRCT20160318027097N10). It is important to mention that patients' consent to participate in the study was obtained at baseline.

\section{References}

1. Adams HP Jr, del Zoppo G, Alberts MJ, Bhatt DL, Brass L, Furlan A, et al. Guidelines for the early management of adults with ischemic stroke: a guideline from the American Heart Association/American Stroke Association Stroke Council, Clinical Cardiology Council, Cardiovascular Radiology and Intervention Council, and the Atherosclerotic Peripheral Vascular Disease and Quality of Care Outcomes in Research Interdisciplinary Working Groups: The American Academy of Neurology affirms the value of this guideline as an educational tool for neurologists. Circulation 2007; 115(20): e478-534. doi: 10.1161/circulationaha.107.181486.

2. Kolominsky-Rabas PL, Sarti C, Heuschmann PU, Graf C, Siemonsen S, Neundoerfer B, et al. A prospective community-based study of stroke in Germany--the Erlangen Stroke Project (ESPro): incidence and case fatality at 1, 3, and 12 months. Stroke 1998; 29(12): 2501-6.

3. American Heart Association. Heart disease and stroke statistics-2011 update. Circulation 2011; 123(4):e18-209. doi: 10.1161/CIR.0b013e3182009701

4. Yip TR, Demaerschalk BM. Estimated cost savings of increased use of intravenous tissue plasminogen activator for acute ischemic stroke in Canada. Stroke 2007; 38(6): 1952-5. doi: 10.1161/strokeaha.106.479477.

5. Broderick J, Brott T, Kothari R, Miller R, Khoury J, Pancioli A, et al. The Greater Cincinnati/Northern Kentucky Stroke Study: preliminary first-ever and total incidence rates of stroke among blacks. Stroke 1998; 29(2): 415-21.
6. Marx J, Hockberger R, Walls R. Rosen's Emergency Medicine - Concepts and Clinical Practice, 2-Volume Set. 8th ed. Philadelphia: Elsevier Health Sciences; 2013.

7. Hosseini AA, Sobhani-Rad D, Ghandehari K, Benamer HT. Frequency and clinical patterns of stroke in Iran Systematic and critical review. BMC Neurol 2010; 10: 72. doi: 10.1186/1471-2377-10-72.

8. Smith RW, Scott PA, Grant RJ, Chudnofsky CR, Frederiksen SM. Emergency physician treatment of acute stroke with recombinant tissue plasminogen activator: a retrospective analysis. Acad Emerg Med 1999; 6(6): 618-25.

9. Boudreau DM, Guzauskas GF, Chen E, Lalla D, Tayama D, Fagan SC, et al. Cost-effectiveness of recombinant tissuetype plasminogen activator within 3 hours of acute ischemic stroke: current evidence. Stroke 2014; 45(10): 3032-9. doi: 10.1161/strokeaha.114.005852.

10. Khosravi A, Farzadfard MT, Abdollahpour A. Frequency of stroke patients qualified for recombinant tissue plasminogen activator (r-TPA) injection and limitations in Zahedan 2016. Int J Basic Clin Pharmacol 2018; 7(1): 7-10. doi: 10.18203/2319-2003.ijbcp20175670.

11. Delavar Kasmaei H, Baratloo A, Nasiri Z, Soleymani M, Oraee Yazdani M. Recombinant tissue plasminogen activator administration in patients with cerebrovascular accident; a case series. Arch Neurosci 2015; 2(2): e23315. doi: 10.5812/archneurosci.23315.

12. Mojdehipanah H, Yazdi Z, Nasiri MS, Azizlo Z. Barriers to delivery of tissue plasminogen activator for patients with acute ischemic stroke. Feyz 2015; 19(2): 169-76. [In Persian].

13. Tintinalli JE, Krome RL, Ruiz E. Emergency medicine: a comprehensive study guide. Adv Emerg Nurs J 1992; 14(3): 74.

14. Demaerschalk BM, Yip TR. Economic benefit of increasing utilization of intravenous tissue plasminogen activator for acute ischemic stroke in the United States. Stroke 2005; 36(11): 2500-3. doi: 10.1161/01.str.0000185699.37843.14.

15. Meiner Z, Sajin A, Schwartz I, Tsenter J, Yovchev I, Eichel $\mathrm{R}$, et al. Rehabilitation outcomes of stroke patients treated with tissue plasminogen activator. PM R 2010; 2(8): 698702. doi: 10.1016/j.pmrj.2010.04.029.

16. Emberson J, Lees KR, Lyden P, Blackwell L, Albers G, Bluhmki E, et al. Effect of treatment delay, age, and stroke severity on the effects of intravenous thrombolysis with alteplase for acute ischaemic stroke: a meta-analysis of individual patient data from randomised trials. Lancet 2014; 384(9958): 1929-35. doi: 10.1016/s0140-6736(14)60584-5.

17. Pashapour A, Atalu A, Farhoudi M, Taheraghdam AA, Sadeghi Hokmabadi E, Sharifipour E, et al. Early and intermediate prognosis of intravenous thrombolytic therapy in acute ischemic stroke subtypes according to the causative classification of stroke system. Pak J Med Sci 2013; 29(1): 181-6. doi: 10.12669/pjms.291.2897.

18. Hatamabadi HR, Mansouri H, Asarzadegan F, Shojaee M. Barriers to on time delivery of thrombolytic therapy. Journal of Mazandaran University of Medical Sciences 2013; 23(102): 107-10. [In Persian].

19. Campbell BCV, Donnan GA, Lees KR, Hacke W, Khatri P, Hill MD, et al. Endovascular stent thrombectomy: the new standard of care for large vessel ischaemic stroke. Lancet Neurol 2015; 14(8): 846-54. doi: 10.1016/s14744422(15)00140-4. 